\title{
Value Chain Analysis and Competitive Advantage
}

\author{
Prescott C. Ensign
}

The linkages in value chains can be finely tuned to gain a competitive edge.

All firms make decisions that affect their competitive position and profitability. Strategic planning is the organizational process of making these important decisions. It is undertaken in an effort to help the firm position itself against its competitors in the pursuit of competitive advantage. Porter [1] suggests that value chain analysis can be a useful approach in developing strategy.

Value chain analysis can be used to formulate competitive strategies, understand the source(s) of competitive advantage, and identify and/or develop the linkages and interrelationships between activities that create value. This paper offers a better understanding of the kinds of linkages and interrelationships that exist or can be developed between value chain activities.

Competitive strategies (business strategies) are based on integrating activities in the value chain. For example, within Michelin there is a distinct interconnectedness of $R \& D$, production, marketing, and information systems. Since there are many linkages and interdependencies among activities, the ability to co-ordinate interrelationships is critical to achieving competitive advantage. Integration can increase a firm's capacity to implement strategies, e.g., respond quickly and effectively to market forces, improve its response to customer needs, and reduce costs. Competitive strategies focus on activities needed to increase the value of a product or service.

Porter [2] suggests that in an environment with increasing competition firms may need to co-ordinate the sharing of activities

Prescott C. Ensign is a Research Fellow at the Hautes Études Commerciales in Montréal, Quebec, Canada.

Ensign, P.C. (2001) Value Chain Analysis and Competitive Advantage: Assessing Strategic Linkages and Interrelationships. Journal of General Management. 27(1): 18-42. 
between organizational sub-units. Customer demands and market forces may require that coordination move beyond integration between the traditional departments, product lines, or geographic structure. A firm may need to formulate strategies and manage interrelationships within the same function/activity between different units, e.g., between business units and geographical area units. General Motors serves as a case in point; a model marketed in the US may be designed in Germany, assembled in South Korea with parts from Japan, Singapore, and Taiwan, and have advertising formulated in the UK. This simple description which appears as a sequential order does not convey the degree to which the process is a network of collaborations. Strategies may be needed that centralise co-ordination across subunits to achieve competitive advantage at the corporate level. Such corporate strategy has been referred to as horizontal strategy.

The aim of this paper is to provide a more comprehensive way to define and categorise the various kinds of linkages and interrelationships between activities of the value chain. Three methods for the classification of interrelationships are suggested. These are based on the kinds of linkages between activities:

- by participants in linkage;

- by purpose of linkage, and

- by kind of strategic linkage.

The remainder of this paper is organized into the following sections: Competitive Strategy and Competitive Advantage; Understanding Linkages and Interrelationships; and Implications of Strategic Linkages and Value Chain Analysis for Strategic Planning.

\section{Competitive Strategy and Competitive Advantage}

Firm profitability is a function of industry attractiveness (structure) and the firm's relative position within that industry. A strong relative position implies that the firm has a competitive advantage that can be sustained against attacks by competitors and changes in the industry. The search for industry attractiveness and an analysis of competitors can guide a firm in its choice of competitive strategy.

Competitive strategy is based on the premise that the firm has a number of ways in which competitive advantage can be achieved.

'Both industry attractiveness and competitive position can be shaped by a firm ... a firm can clearly improve or erode its position within an industry through its choice of strategy. Competitive strategy, then, not only responds to the environment but also attempts to shape that environment in a firm's favor.' [2] 
A firm's search for competitive advantage begins with the strategic choices it makes regarding its position within an industry. But it must also understand how to translate competitive strategy into competitive advantage. A firm must determine how to implement the competitive strategy chosen in order to achieve competitive advantage.

Competitive advantage is based on how value is created or arrived at in carrying out a competitive strategy. Value is determined by the unique combination of attributes - in a product or service - which are important to a customer. For example in terms of automobiles, the value of a Ferrari or a Fiat is determined only by customer perception. Whether Ferrari or Fiat, the value must exceed the firm's cost of creating it. Value is added as specific activities or functions are performed to provide a product (or service). Competitive strategy and competitive advantage can result from any number of different configurations of activities within the firm. For a firm in the automobile industry with expertise in design, this activity may be combined with an array of activities. For example, those responsible for styling may work closely with such disparate activities as materials procurement or advertising.

Competitive strategy must be tied to how a firm can sustain a competitive position and achieve long-term profitability. In developing a competitive strategy, a firm generally has two choices. Its competitive position can be based on: cost leadership or specialisation. A firm's choice of strategy generally falls into one of three generic strategies: cost-leadership, differentiation, or focus. A generic strategy does not lead to superior performance unless it is sustainable vis-à-vis the firm's competitors. The sustainability of a firm's competitive advantage means a firm must possess some barriers that make imitation of its strategy difficult for competitors. Causal ambiguity is one way to describe such barriers to imitability [4]. For a firm to obscure understanding may mean that its operations are not publicised externally or not even fully articulated internally. This suggests that a successful firm may not want to fully explore its superior recipe of styling and materials procurement. The candour with which companies such as Dow Chemical and Ericsson 'reveal secrets' is indication that competitors would be unlikely to reproduce these advantages even with insider assistance. The processes and formulae are simply too complex and the knowledge too tacit. Such corporations find the internal sharing of embedded knowledge challenging. A firm must find ways to create value that distinguish it from its competition. It must find ways to capitalise on its core competences. An enterprise must invest its resources in a way that will provide a sustainable competitive advantage.

Reed and DeFillippi [5] state that competitive advantage is linked to competence developed within the firm, Hofer and Schendel [6] state that competitive advantage is the unique position a firm develops relative 
to its competitors through its patterns of resource deployment. Competitive advantage and performance are directly linked.

Until recently, competitive advantage and distinctive competence have been viewed as part of the development of strategy. These concepts have been viewed as independent variables (inputs) —with performance as the dependent variable (an outcome or result). However, competitive advantage can be viewed as the purpose of strategy—the outcome or result [7].

\section{Value chain model}

Value chain analysis can be a useful tool as a firm seeks to achieve competitive advantage. A value chain is a way of conceptualizing the activities that are needed in order to provide a product or service to a customer. It depicts the way a product gains value (and costs) as it moves along the path of design, production, marketing, delivery, and service to the customer.

The value chain model shows the particular configuration of activities that are needed to create value in a product or service. The configuration of these activities - and the resulting product or service - will be a unique to a specific unit or firm. Competitive advantage can result from the way discrete activities are performed along the value chain.

Porter [8] introduces a generic value chain model that is set in the context of a traditional manufacturing firm. It includes the primary activities of: inbound logistics, operations, outbound logistics, marketing and sales and service. It also includes the support activities of: infrastructure of the firm, human resource management, technology development and procurement. This mapping of activities need not stop with the simple sliced polygon as originally proposed. A more developed interpretation may incorporate greater detail by describing them through time and space. That is, such processes may not be strictly lineal but may be iterative (with feedback, flexibility, and learning) and may occur over some physical distance. While this paper will stick with the proven term 'value chain', hesitation must be noted as the second word - chain - conjures up notions of strict lineal sequence. Value may in fact be accumulated as layers overlapping one another without distinct separation or clear demarcation among activities. Value-generating actions may resemble a spider web or a three-dimensional network (a cloud of relationships rather than a chain. The pharmaceutical industry has been characterised as a web created by new links in the traditional chain [9]. Infomediaries ('go betweens' and purveyors of information) in this industry allow traditional links to be skipped over as they provide direct conduits between pharmaceutical firms and patients. Internet infomediaries empower patients to be better informed and more active in managing their health $[10]$. 
O'Sullivan and Geringer [11] describe this chain of activities as the natural value chain. It includes what the firm has to accomplish (with its resources) to achieve its competitive strategy. These activities (what the firm has to accomplish) are described as the value chain stages. They describe the value chain 'interrelationships' as the commonalities and interdependencies between the stages. They use a contrived value chain to describe how the resources of the firm are used to accomplish its strategy. The contrived value chain shows how the natural value chain is implemented.

'There are many ways an enterprise can operationalize the natural value chain, but all are constrained by the limitations of the available technical and human resources. As those limitations are overcome, the ability of the contrived chain to create value increases accordingly.' [12]

Armistead and Clark [13] examine the use of the value chain in designing service operations strategy. They suggest a resource activity map - a generic map that can be applied to any service operation. It is based on a service delivery system that includes three dimensions: resources used, configuration of the resources, and service process flow.

\section{Value chain analysis and strategic planning}

The value chain approach to planning can provide rich description as well as numerical analyses of strategically important activities. An understanding of their impact on the business unit (or firm in the case of a single industry business) is critical to achieving competitive advantage. A number of studies that take a resource-based view of the firm (e.g., $[14,15,16])$ implicitly provide concepts that are important in understanding value chain analysis and its use in strategy formulation and planning.

To be useful, value chain analysis must be a worthwhile method of dividing the firm into activities in order to understand their impact on the business unit. The value chain can be employed to explore the impact that each activity individually can have on cost behaviour and differentiation. Since cost and differentiation advantages are derived from the way resources are configured in the value chain, value chain analysis is an excellent tool to use in strategic planning. Xerox' assessment of its supplier relationships led to a reduction in number of suppliers-from more than 5000 to fewer than 500. Xerox also consciously reduced the number of bids it receives. Such streamlining of procurement resulted in significant savings. At the same time, Xerox moved toward integration of operations and standards across functions and physical locations.

Value chain analysis is also a way of understanding how activities collectively impact the business unit. It provides a perspective on how all 
(or some group of) the activities contribute to the process of adding value to a product or service. It emphasises the importance of all activities, the primary as well as supporting activities. It emphasises the importance of co-ordinating the linkages and interrelationships among activities. This perspective is important in strategy formulation and planning whether for traditional manufacturing, knowledge-based, e-commerce: or service-providing enterprises. 'In the past, the automobile industry value chain was a marvel of compartmentalization' [17]. Business systems in this industry are 'breaking up' or 'unfreezing' only to form in new configurations. Linking people and processes across the value chain, around the globe is an increasing concern [18].

As a framework for developing strategy, value chain analysis has several distinct characteristics. Both the dissecting of activities and the synthesis of activities provide insight, detail, and an overall perspective. This results in:

(1) an emphasis on understanding the source(s) of sustainable competitive advantage;

(2) a way to identify the linkages and interrelationships between activities which create value; and

(3) a focus on the formulation of well-founded (competitive) strategies.

Using the value chain approach can result in an explicit and coherent planning process.

The first advantage of using the value chain approach in strategic planning is related to the need to understand the source(s) of competitive advantage. The roots of this approach are in microeconomics. The firm is viewed as a collection of discrete yet related activities. Some of these activities are not traded in external markets. This view suggests that these activities can be the source of economic rents (above normal rates of return) a firm obtains from these firmspecific assets. These non-traded activities can also create entry barriers or cost disadvantages for competitors. A first step in strategy formulation is to identify the specific activities that are the source of superior profits.

Every firm performs a variety of activities in transforming raw materials and primary goods into final products. Although necessary (from the standpoint of delivering the product or service to the customer) most of these activities do not distinguish a firm from its rivals. Competitive advantage must be based on those activities in which a firm has proprietary access to scarce resources (e.g., skills, assets, intellectual capital distribution networks, etc.). A firm must guard, nurture, and build those specific areas that are the source of sustainable competitive advantage Value chain analysis is such a window to these firm-controlled assets. In 
the liquid crystal display (LCD) industry, successful firms such as NEC, Sharp, and Toshiba know that within the value chain, it is the R\&D function that holds the key to profits and longevity.

The second advantage of looking through the lens of the value chain is the emphasis on complex linkages and interrelationships. These are: internal linkages within the value chain (interrelationships between activities in the same business unit); external linkages - between a business unit and another (an outside) firm; and linkages between one business unit and another unit in the same firm. These linkages and interrelationships can provide opportunities for joint

optimisation and co-ordination. For example, within Ericsson, R\&D groups do not operate with local (unit) efficiency as their ultimate goal, but with global (corporate) optimisation in mind. That is, local maximisation may be abandoned for the good of the entire network. According to Sven Borgstrom, General Manager of Ericsson Research Canada, his operation is a net exporter of knowledge to the remainder of the organization. He is also quick to point out that Ericsson operates with some elements of a free market within the company-there is competition (as well as co-operation) among groups [19].

The third distinctive characteristic of the value chain approach is its focus on the formulation of firm-specific strategies. That is a strategy tailored to the firm's constraints and talents. Cost leadership as a strategy requires that a firm possesses greater efficiency than its rivals. A differentiation strategy requires that a firm add more to buyer value than to its own costs. A strategy of focus requires that a firm pursue cost leadership or differentiation in a narrowly defined (segmented) market. The choice of an appropriate strategy and the successful implementation of that strategy require knowledge of the cost structure of the firm and its rivals. To this end a firm will decompose or reconstruct a competitor's value chain.

Since the primary interest in this paper is related to the linkages and interrelationships between activities of the value chain, this paper will focus on the advantages of using value chain analysis in strategic planning. The following sections in this paper are designed to provide an understanding of: the kinds of linkages and interrelationships among value chain activities; and how these linkages and interrelationships influence strategy and ultimately gain competitive advantage.

\section{Understanding Linkages and Interrelationships}

Although value chain activities are the primary means of achieving competitive advantage, it is important to understand that the value chain is not a collection of independent activitiessomething the distinct boxes within Porter's now famous polygon seem to have promulgated. The benefits of dividing the various activities pictorially may not entirely 
counter the misperceptions created of their power to stand alone. The reduction in the separation of functions by organizations attests to this. There exist linkages and interrelationships among activities in the value chain. Competitive advantage can result from the way these linkages among activities are managed as well as from the individual activities themselves. Managing value activities and managing linkages between value activities are different strategic problems.

Linkages can affect competitive advantage in two ways: optimisation and co-ordination. Optimisation can be defined as an act, a process, or an approach to making something (design, system, or decision) as fully perfect, functional, or effective (strategically efficient) as possible. To understand optimisation of linkages in the context of the firm. Porter's [20] definition of linkages seems applicable: 'linkages are relationships between the way one value activity is performed and the cost or performance of another.'

The idea of optimisation seems to be related to the concept of trade-offs and equifinality, i.e., different ways to achieve the same overall result. The choices or alternatives made in performing a value activity can have an impact on the performance of an activity elsewhere. This implies that a firm must optimise the linkages in the value chain in order to achieve competitive advantage. At Volkswagen, not only do activities in production affect one another but they also impact those in marketing, and vice versa. It is important that activities not only be examined with value creation in mind, but a critical eye tuned to the possibility that a portion of the collage of existing activities may be destroying value or draining capital. If so, such activities need to be rethought - this may result in rearrangement or outsourcing. Hence, Volkswagen's retreat from production in Canada might be regarded as a prudent course of action.

Shapiro, Singhal, and Wagner [21] report on an effort to develop an advanced decision support system (DSS) for a consumer products company in the process of acquiring another firm. Mathematical programming and information technology can be used to optimise the activities in the value chain. They suggest three benefits of using a mathematical programming model to optimise the value chain. It can provide: the analytical power needed to evaluate complex integrated planning problems; a structure for the way data should be organized for decision making; and the data needed for control and budgeting that will reflect an allocation of resources across the firm.

Porter [22] suggests that competitive advantage can also be achieved by the co-ordination of linkages. In order to achieve competitive strategy, some degree of integration between - and at a minimum awareness of - value activities is required. Integration of activities is 
needed to manage interdependencies. The ability of management to co-ordinate linkages often reduces cost or enhances differentiation. Co-ordination of linkages implies that a firm's cost or differentiation can result from the way linkages are managed as well as the efforts to reduce cost or improve performance in each value activity individually.

'Much of the recent change in philosophy towards manufacturing and towards qualitystrongly influenced by Japanese practice - is a recognition of the importance of linkages.' [23]

Porter [24] classifies linkages within the value chain as those between primary and support activities or between the primary activities themselves. He describes the traditional methods of outsourcing (suppliers and distribution channels) as vertical linkages. He also suggests that the diversified firm or multinational firm may have overlooked linkages - in this case horizontalfor sharing activities or skills between different business or geographic units. These interrelationships are the opportunities that can be developed to achieve synergy and competitive advantage.

Although Porter [25] describes these linkages and interrelationships at some length, he does not provide meaningful definitions for these concepts. He does not provide a comprehensive method for understanding the different kinds of linkages and interrelationships. In order to understand the differences and the impact they can have on the firm, these concepts must be defined and a classification system established.

Given the critical importance of recognising and managing linkages, it is important to have a clear understanding of the kinds of linkages and interrelationships that exist or can be developed to achieve competitive advantage. The ability to identify existing linkages as well as to develop potential ones is crucial to competitive advantage. If opportunity exists to yield a sustainable advantage, a firm must have clear definitions and ways to describe the different kinds of linkages and interrelationships.

This section is an attempt to organize and define the linkages and interrelationships among activities in the value chain. Three ways to classify interrelationships are put forth: by participants in linkage, by purpose of linkage, and by kind of strategic linkage. These three ways to describe linkages are related to the questions of where, why, and how linkages occur. Answers to these questions provide a better understanding of the role linkages play in achieving competitive advantage.

\section{Classification of Interrelationships by Participants in Linkage}

The first method of classification (Table 1) is used to illustrate that interrelationships can result from a linkage with a participant from the same firm (internal) or an outside firm (external). These interrelationships 
can result from linkages among activities across one value chain or among two or more different value chains. Based on the participants in the linkage, interrelationships can result from internal linkages or external linkages.

Table 1: Classification of Interrelationships by Participants in Linkage

\begin{tabular}{|c|c|}
\hline Internal Linkage & External Linkage \\
\hline - Intra-Unit Interrelationship & $\bullet$ Inter-Firm Interrelationships \\
- Intra-Firm Interrelationship & $\bullet$ Network Interrelationship \\
- Inter-Unit Interrelationship \\
- Business Unit \\
- Geographic Unit
\end{tabular}

\section{Internal linkages}

In order to bring a product to market or provide a service, every activity in the value chain can be performed within the firm (internal) or by a source outside the firm (external). An internal linkage is one that describes a relationship that can occur when value activities are performed within one unit or between two units in the same firm. Internal linkages result in three different kinds of interrelationships: intra-unit interrelationships, intra-firm interrelationships, and interunit interrelationships.

An intra-unit interrelationship (internal integration) can occur when the activities in question in one unit's value chain are performed by that one unit. This interrelationship results from linkages within one value chain. Question for the administrator: should all activities be performed solely within the unit in question?

An intra-firm interrelationship (internal outsourcing) can occur when the activity in question in one unit's value chain is provided by another unit in the same firm. These interrelationships result from an internal linkage between two units (two value chains) of the same firm. This linkage results in the one-way flow of materials or services. This is quite different from an inter-unit interrelationship that describes the two-way sharing that can occur between two units in the same firm. Question for the administrator: should the unit in question receive from (or provide to) other units within the firm?

An inter-unit interrelationship (internal resource sharing) can occur when sharing takes place between two different units of the same firm. Sharing of activities or skills takes place between the two value 
chains. Since these internal linkages are generally between different business or geographic units, they are described as: business unit interrelationships (e.g., linkages between different product or market units in a diversified firm); or geographical area unit interrelationships (e.g., linkages between different geographic units or subsidiaries in a multinational firm). St. John and Harrison [26] find that it is possible for a firm to realise improved performance from resource sharing 'through explicit commitment to co-ordination.' Question for the administrator: should the unit in question have a reciprocal exchange relationship with other business or geographic units in the firm?

\section{External linkages}

An external linkage is one that describes an interrelationship between one unit and an outside (external) firm. External linkages result in two kinds of interrelationships: inter-firm interrelationships and network interrelationships.

An inter-firm interrelationship (external outsourcing) can occur when an activity needed in one unit's value chain is provided by an outside source. It is an external linkage between one unit's value chain and the value chain of another firm. The pharmaceutical industry is experiencing growth in outsourcing partners [27]. Outsourcing for such firms may include some or all portions of the following activities: product development, manufacturing, warehousing, and customer analysis and management [28]. Such firms are increasingly avoiding building costly and time-consuming in-house capabilities. 'Instead, they form partnerships that coalesce and dissolve with each new project' [29]. Forrester Research projects the outsourcing trend to grow as 'not-at-all' manufacturing replaces 'just-in-time' manufacturing. Cisco Systems owns two of the 30 plants that produce its products. Question for the administrator: should the unit in question receive from (or provide to) units in other firms?

A network interrelationship (external resource sharing) can result from the linkage between a unit/firm and one or more outside (external) firms. These interrelationships are designed to create a new value chain that is shared by all partners. Network interrelationships result in a different organizational form - alliance or network organization. Question for the administrator: should the unit in question be sharing with other firms?

\section{Classification of Interrelationships by Purpose of Linkage}

A second way to classify interrelationships is by purpose of the linkage (Table 2). It is another way to understand the interrelationships that can exist in a firm. The same interrelationships that are listed in the first chart may be classified using the intended purpose of the linkage. These linkages are: 
(1) task performance linkage - to perform or carryout the value activities included in one unit's value chain;

(2) sharing linkage - to share an activity or skill between two units of the same firm; and

(3) network linkage - to create or perform discrete activities in a new (shared) value chain.

Table 2: Classification of Interrelationships by Purpose of Linkage

\begin{tabular}{|c|c|c|}
\hline Task Performance Linkage & Sharing Linkage & Network Linkage \\
\hline $\begin{array}{c}\text { Intra-Unit Interrelationship } \\
\text { Integration }\end{array}$ & $\begin{array}{c}\text { Inter-Unit Interrelationship } \\
\text { Business Unit } \\
\text { Geographic Unit } \\
\text { Co-ordination }\end{array}$ \\
$\begin{array}{c}\text { Intra-Firm Interrelationship } \\
\text { Outsourcing }\end{array}$ & $\begin{array}{c}\text { Network Interrelationship } \\
\text { Co-ordination }\end{array}$ \\
$\begin{array}{c}\text { Inter-Firm Interrelationship } \\
\text { Outsourcing }\end{array}$ & & \\
\hline
\end{tabular}

The differences in these linkages result from different strategic decisions. A unit or firm has a number of strategic choices as well as alternative ways of implementing these strategies. This method of classification points to the different configurations that result from these decision. It also highlights the different ways strategies are implemented to achieve competitive advantage.

\section{Classification of Interrelationships by Kind of Strategic Linkage}

A third method of classification (Table 3) illustrates that linkages and interrelationships are directly related to the kind of strategy being pursued. Two categories are used to classify interrelationships: business strategy linkages and corporate strategy linkages.

Table 3: Classification of Interrelationships by Kind of Strategic Linkage

\begin{tabular}{|c|c|}
\hline Business Strategy Linkage & Corporate Strategy Linkage \\
\hline - Intra-Unit Interrelationship & $\begin{array}{l}\text { - Inter-Unit Interrelationship } \\
\text { - Business Unit } \\
\text {-Geographic Unit }\end{array}$ \\
\hline $\begin{array}{l}\text { - Intra-Firm Interrelationship } \\
\text { - Inter-Firm Interrelationship }\end{array}$ & - Network Interrelationship \\
\hline
\end{tabular}




\section{Business strategy linkages}

Interrelationships based on business strategy linkages occur where the activity being performed is a necessary part of the chain of activities in one value chain. These interrelationships - which add value to a product or service in one unit-involve the activities of one unit's value chain. All activities performed are designed to contribute to the strategy in that one unit. Three kinds of interrelationships result from these business strategy linkages: intra-unit interrelationships (internal integration), intra-firm interrelationships (internal outsourcing), and inter-firm interrelationships (external outsourcing).

\section{Corporate strategy linkages}

Interrelationships based on corporate strategy linkages occur when an activity or skill is shared between two units in the same firm or a unit and another firm. These interrelationships are designed to achieve competitive advantage at the corporate level. These linkages can result in two kinds of interrelationships: inter-unit interrelationships (a linkage with another business unit or geographic unit in the same firm) and network interrelationships.

Business strategy linkages and corporate strategy linkages result in quite different interrelationships. Two depictions are designed to show these differences: a summary of business strategy interrelationships (Figure 1) and a summary of corporate strategy interrelationships (Figure 2).

Figure 1: Summary of Business Strategy Interrelationships*

Intra-Unit Interrelationship (Internal Integration)

- Internal Linkage

- Task Performance Linkage

- Business Strategy Linkage

Intra-Firm Interrelationship (Internal Outsourcing)

- Internal Linkage

- Task Performance Linkage

- Business Strategy Linkage

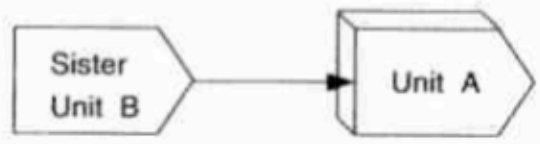

Inter-Firm Interrelationship (External Outsourcing)

- External Linkage

- Task Performance Linkage

- Business Strategy Linkage

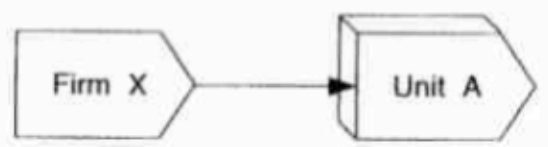

- These interrelationships, hased on business strategy linkages, occur where the activity being performed is a necessary part of the chain of activities in one value chain. 
Figure 2: Summary of Corporate Strategy Interrelationships*

Inter-Unit Interrelationship (Internal Resource Sharing)

- Internal Linkage

- Sharing Linkage

- Corporate Stralegy Linkage

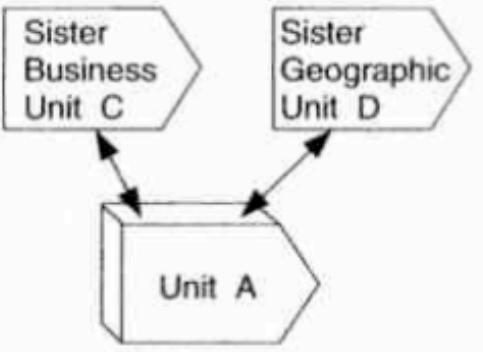

Network Interrelationship (External Resource Sharing)

- External Linkage

- Network Linkage

- Corporate Strategy Linkage

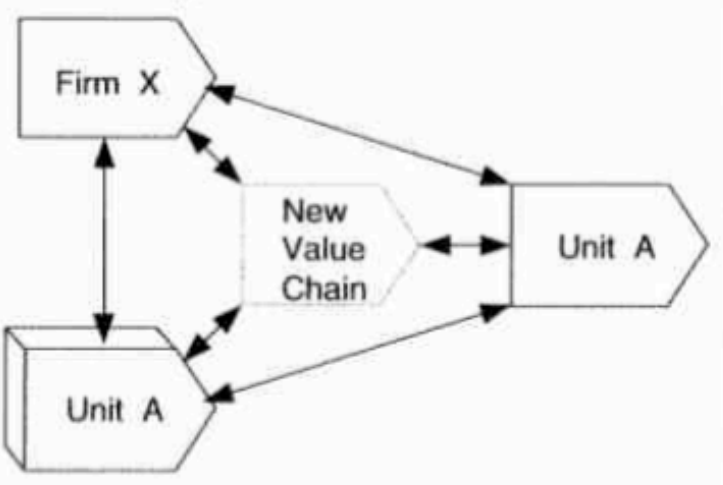

These interrelationships, based on corporate strategy linkages, oceur when an activity or skill is shared between value chains in the same firm (inter-unit internelationships) or a unit and one or more firms (network interrelationship).

\section{Implications of Strategic Linkages and Value Chain Analysis for Strategic Planning}

The traditional approach to strategic planning is to develop strategy at two levels-business and corporate. The goal of business strategy is to obtain superior performance and above-average returns at the strategic business unit (SBU) level. Business strategy is often called competitive strategy because it is viewed as the primary way for a firm to achieve competitive advantage.

Corporate strategy defines the overall goals of a firm. It is viewed as a plan for making the firm a congruent whole, i.e., worth more than the sum of its parts. It has traditionally focused on adding value by channelling investment into businesses that compete in industries with attractive structures. This view of corporate strategy may no longer be sufficient in today's environment. In some industries, a firm may need to identify and manage linkages that can provide competitive advantage at the corporate level for the firm as a whole rather than just at the business unit level. 
Value chain analysis allows a firm to examine the linkages and interrelationships that can provide these two means of arriving at competitive advantage. Based on an examination of business strategy linkages and corporate strategy linkages, competitive advantage is achieved in quite different ways. With business strategy linkages, competitive advantage is based on an individual unit's business (competitive) strategy. With corporate strategy linkages, competitive advantage is based on building interrelationships that result in sharing or networking between two or more units/firms. These interrelationships are based on achieving collaboration and coordination between the different parties in the relationship.

Figure 3 is designed to summarise the three classifications of interrelationships by: participants in linkage, purpose of linkage, and kind of strategic linkage. It illustrates the alternatives available to one unit and the kinds of interrelationship that result from these linkages.

Figure 3: Summary of Strategic Alternatives

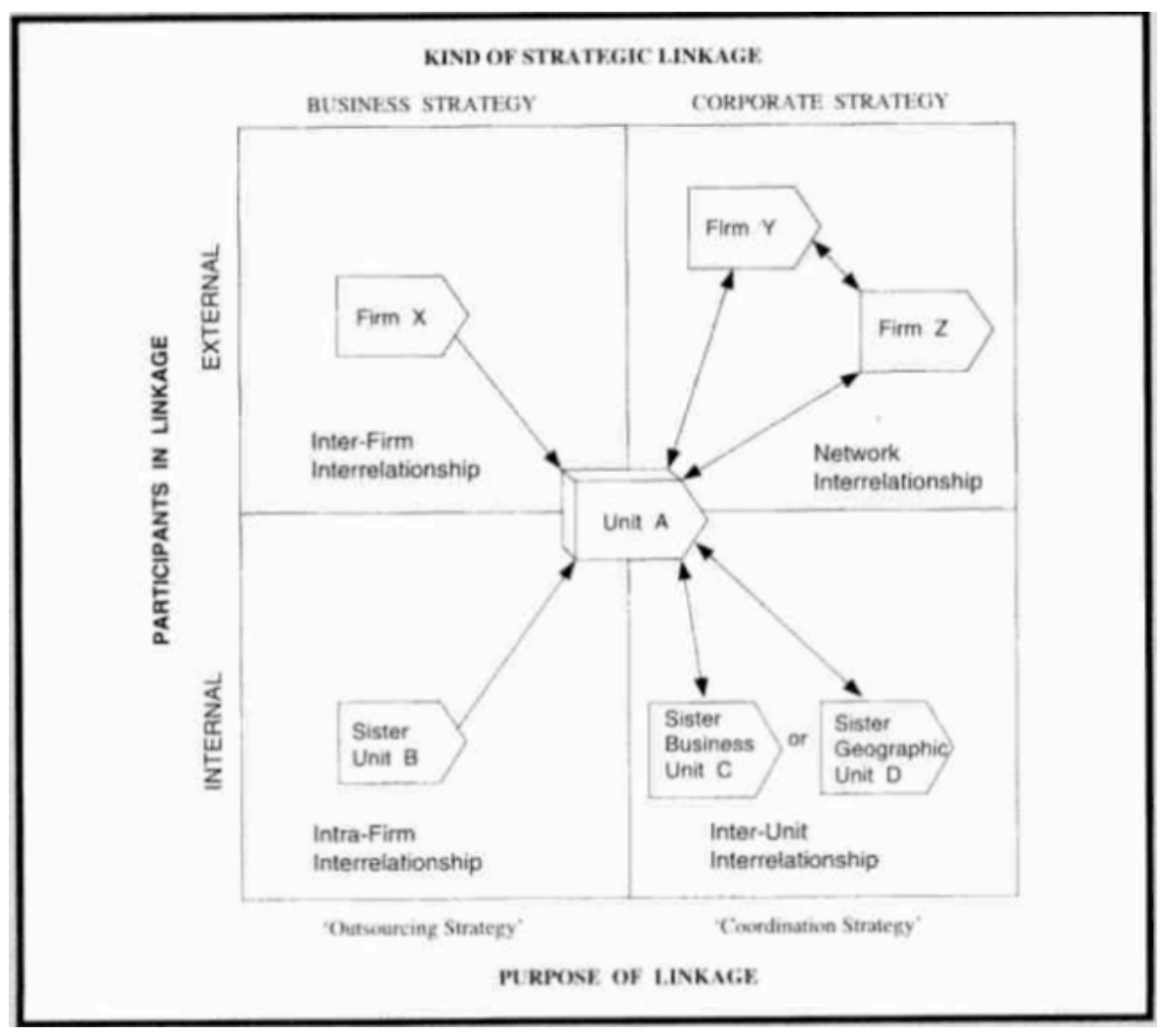

\section{Business strategy linkages and value chain analysis}

The interrelationships that result from business strategy linkages are based on performing an activity that is needed in one unit's value chain. 
The primary decision facing a business unit is who will perform an activity. A unit has a number of choices. An activity can be performed: within the one unit (intra-unit), by another unit of the same firm (intra-firm), or by an outside firm (inter-firm).

Another major decision is related to how the activities of the value chain will be coordinated. When examining the activities that must be completed in the value chain, the unit must make explicit integration choices. No matter what choice a unit makes regarding who will perform the activity - some degree of co-ordination/integration is needed. The problems that must be faced are related to the efficient operation of each part of the total effort and also to the co-ordination of each phase into an overall plan that is responsive to changing conditions. Integration may depend on the firm's need to:

(1) increase its capacity to respond quickly and effectively to market forces;

(2) improve its responsiveness to customer requirements, or

(3) reduce costs.

Although the requirements will vary in a particular industry, firms operating in today's competitive environment face an increasing need to focus on customer demands and changing market forces. A firm's ability to integrate activities in the value chain can be an important source of competitive advantage. Kevin O'Laughlin of Ernst \& Young provides a warning and signs of encouragement: the 'reality is that we've been focused very much on the linkages one tier at a time over the last five or 10 years ... I'm intrigued by some of the new supply-chain structures ... which really get for the first time to an enabling, sharing infrastructure' [30].

The complexity of the interrelationship or interdependence, however, determines the integration that is needed. It may be for this very reason that small and midsize firms are less likely to have value-chain strategies. Such firms often do not have the resources to devote to such pursuits; the good news is that these firms where value-chain analysis has a presence do experience the benefits just as provided in large firms. Each of the choices related to who will perform the activity will require a different degree of co-ordination. A matrix has been designed to illustrate the direct relationship between the complexity of the interrelationship and the need for co-ordination (Figure 4). The degree of integration/co-ordination increases with increasing complexity. Dave Hubbard of Iomega admits the external relationships are more difficult than internal ones: 'when you're establishing a value chain, what you're asking people to do it yield a bit of control to the chain. ... until we can show a pervasive win-win situation and a track record to meet commitments, we're getting a lot of scepticism' [31]. 
Figure 4: Difference in the Need for Integration Based on Complexity of Interrelationship

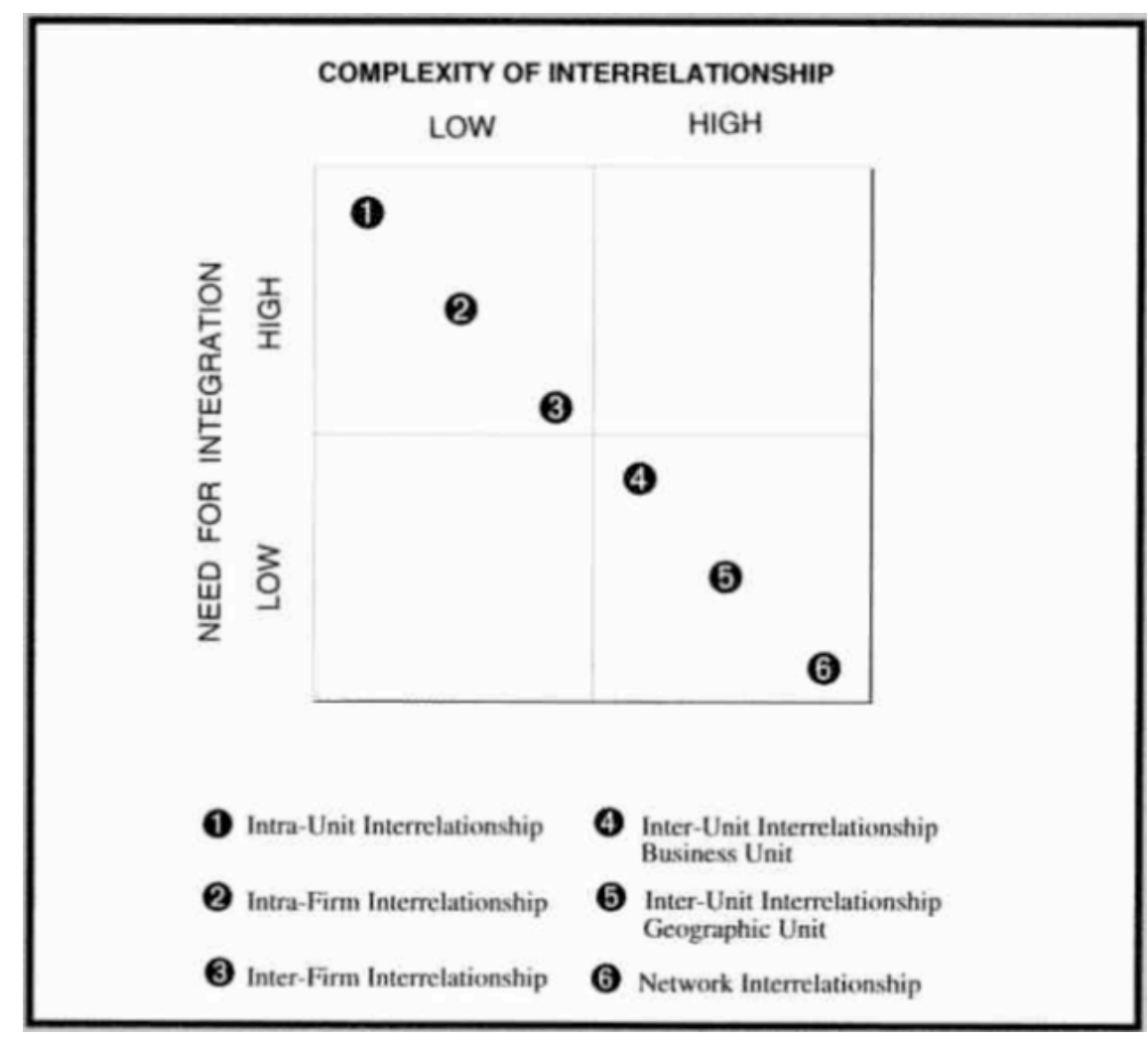

Looking at the business strategy linkages, an intra-firm interrelationship results from an internal outsourcing decision. In the traditional vertically integrated organization, this pattern is generally referred to as 'backward' integration (to a supplier within the firm) and 'forward' integration (to a distribution channel in the same firm). An inter-firm interrelationship is similar. It results from a decision to have an external source (another firm) provide the activity. The linkage extends the chain of activities to the value chain(s) of the outside source (another firm).

With regard to the question of who will perform an activity in one unit's value chain, it is conceivable that every value activity could be performed by outsourcing (external or internal). In recent years there has been an increasing interest in the issue of de-integration or disintegration (i.e., the virtual corporation). The key issue for designing a virtual corporation or network organization is the partner selection process: identifying candidates, considering them both individually and collectively, and finally establishing the best portfolio based on criteria of compatibility [32]. A resource-based view of competitive advantage can provide help in reassessing the merits of vertical integration. Mahoney [33] suggests 
that vertical integration can be described in two ways - as vertical financial ownership and vertical contracts. Examining the link between these and the choice of organizational form, he outlines the motives for or potential advantages of vertical integration: transaction costs considerations, strategic considerations, output and/or input price advantages, and uncertainties in costs and/or prices.

The current consensus is that performing everything within the same firm-at least for some industries - may no longer provide the cost efficiency needed to remain competitive. Companies will disintegrate and re-align, often with outsiders: 'In tandem with internal re-arrangement companies will continue to form significant external partnerships in key areas' [34]. To do so, the firm must look at each activity and compare the cost of performing the activity within the same unit or firm, versus having an outside firm perform the activity. If a firm chooses outsourcing, its strategic task is to optimise and co-ordinate linkages (internal and external linkages) in a way that can result in competitive advantage. 'Companies are re-examining what the core requirements are', the 'must haves' of the automaker are being called into question: powertrains, autobodies, final assembly, and even engines [35]. The shuffling of value chain activities is not isolated. The very same suppliers are shedding assets as they too embrace opportunities in new linkages and interrelationships.

Quinn [36] suggests that the firm should concentrate its resources on those activities it does best (or better than others). In his view the shift to de-integration is related to overall changes in industry environment and customer demands. Changes in competitive strategy are needed in response to an environment that is characterised by service, pressures of time-to-market, cost, and globalization. Competitiveness may involve turning over command and control of the value chain to the customer to initiate activities that ripple throughout [37]. The emphasis is on maintaining access to the customer able to click among suppliers. Value chain analysis involves knowing when to be collaborative and when to be combative [38].

Home Depot notified 1,000 suppliers, including Black \& Decker and GE, that it will hesitate to do business with suppliers that also market their products online. Home Depot said it would be happy to partner with them on selling via the Internet, but maintaining the primary relationship with the ultimate customer is Home Depot's obvious rule of engagement. In their work with both manufacturing and service companies, Rockart and Short [39] found that the multi-stage value chain could be collapsed into three primary segments. These major groupings are evident when firms have successfully integrated activities in the value chain. These are:

(1) product development (includes and/or overlaps with design, engineering, purchasing, and manufacturing); 
(2) product delivery (includes and/or overlaps with purchasing, manufacturing, distribution, and sales); and

(3) customer service and management (includes and/or overlaps with distribution, sales, and service).

These three are the targeted areas for activity integration in the value chain. As Rockart and Short [40] indicate: 'interdependence revolves around these three macro-organizational activities'.

\section{Corporate strategy linkages and value chain analysis}

Another major advantage of using value chain analysis is that it helps draw attention to the achievement of competitive advantage at the corporate level. Value chain analysis can help a firm identify new ways to capitalise on its distinctive competences. One way this can happen is by sharing activities and skills between units. Inter-unit interrelationships (internal resource sharing), for example, can expand the learning and knowledge that exists in separate units of a firm. Pickering and Matthews [41] highlight the significance of deploying intellectual property; the enterprise "needs to manage all aspects of its intellectual property for maximum competitive advantage.' Strategic linkages at the corporate level are opportunities for sharing and joint effects. Corporate planning and strategy are needed to identify and develop these linkages and interrelationships. Corporate resources are needed to fund joint projects and programs that can provide competitive advantage for the total firm. Unlike the past, where independence was prized, the future will call for value chains comprising alliance partners competing as single integrated entities [42].

At the corporate level, competitive advantage is achieved in two ways: (1) internal resource sharing (the sharing of activities or skills between units) that can result in increased co-ordination and/or synergy; and (2) external resource sharing (the combination of activities or skills with outside parties) that can result in a new value chain and organizational form (alliance or network). The interrelationships that result from corporate strategy linkages are described as: inter-unit interrelationships and network interrelationships.

Inter-unit interrelationships can result in synergy and competitive advantage for the diversified firm competing in a number of different industries or the multinational firm competing in a number of geographic areas.

Inter-unit interrelationships (internal resource sharing) are based on linkages that result from the sharing of activities or skills between two or more units. Porter [43] describes these interrelationships as: tangible (sharing of activities) and intangible (sharing of skills or knowhow). 
Sharing of activities can result in economies of scale; sharing of skills can result in economies of scope. These are illustrated in Figure 5. Sharing can increase throughput, reduce unit costs, or improve the pattern of capacity utilisation. The potential benefits of inter-unit interrelationships are also shown in Figure 5. With tangible resource sharing (activities), the potential benefits are higher for economies of scale. With intangible resource sharing (skills/know-how), the potential benefits are higher for economies of scope.

Figure 5: Potential Benefits of Inter-Unit Interrelationships

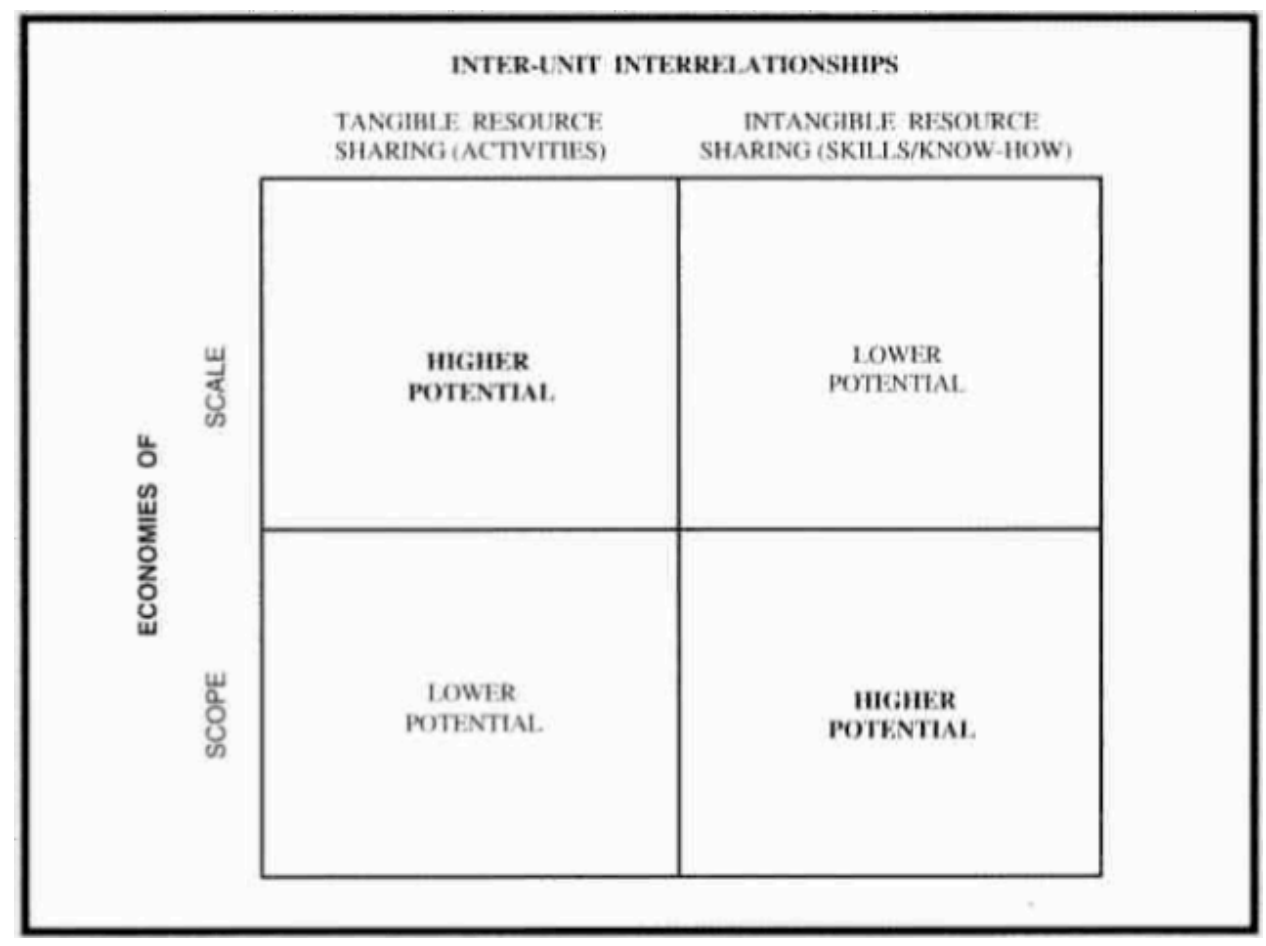

Hall's [44] study of intangible resources is helpful in understanding the impact that resource sharing (inter-unit interrelationships) can have on the firm. He describes intangible resources as capability differentials based on competences (functional differential and cultural differential) and capability differential based on assets (positional differential and regulatory differential). Survey results indicate that skills or competences (employee know-how) are perceived as making a very important contribution to firm success. The sharing of know-how is a crucial occurrence.

These linkages are described as the potential opportunities that can result in competitive advantage. They may not be developed unless a strategic effort is initiated at the corporate level. In many firms, task forces, programs, and projects that cut across functional and/or business unit lines are often used to identify and develop these corporate strategy linkages. The co-ordination of these linkages is not the same as the 
integration decisions needed in managing the activities in a single unit's value chain.

Network interrelationships (external resource sharing) are based on linkages with outside sources that result in the creation of a new value chain and a new organizational form. In some industries, co-operative ventures or alliances have become increasingly important for achieving competitive advantage. As shown in Figure 4 the complexity of these interrelationships and the need for co-ordination are both high. These are not discussed at length since there is an extensive amount of available material in the strategic management literature that can be utilised to understand alliances and network interrelationships. The auto industry has embraced the opportunities afforded in such value chain partnerships: joint R\&D work by DaimlerChrysler, Ford, and Ballard Power; Toyota's agreements with DaimlerChrysler and Volkswagen to use its NOx catalyst system; Bosch's links with Fiat's Magneti Marelli for headlamps; and Magenti Marelli's ventures with Textron and Breed Technologies for interior cockpits [45]. For years, Corning has been touted as an exemplar forks aptitude at partnering. In this age of relationships. Coming's ability to form value-creating links can serve as a strong source of sustainable advantage.

\section{Implications for strategic planning}

Every firm makes strategic decisions based on the needs of the individual units as well as the overall goals of the firm. Decisions in individual business units are primarily designed to implement the business strategy. The value chain shows the activities that are central to the business strategy. No activity in the value chain is totally independent of any other and there exist a number of linkages and interrelationships between activities. The co-ordination of these activities is important in implementing a business unit's strategy. However, one business unit's strategy may hamper another business unit's activities. Barnatt [46] points out that commonalities in information technology now make it possible for those across and between entire value chains to be on common ground thus enabling greater cognisance and integration. There are, however, serious risks to the geometry of end-to-end value chains and tightly connected activities. The British Chamber of Commerce chronicled just how close the economy came to a serious crisis as fuel protests spread from Scandinavia to Spain and Ireland to Israel. Geoff Dossetter, of Britain's Freight Transport Association indicates that with present value chains, if an interruption to the cycle occurs, 'you get a problem sooner rather than later. ... we think companies need to assess whether there are adequate fall-back arrangements' [47].

In any firm, competitive advantage is based on the success of its business strategies in unison. Competitive advantage is based on strategies 
designed to achieve advantage at the corporate level. Some firms may need to identify and develop inter-unit interrelationships and/or network interrelationships that can result in competitive advantage at the corporate level. This will require different organizational mechanisms and processes. For example, lateral mechanisms and processes can provide: new approaches and solutions to old problems; the means to identify, manage, and develop linkages; and new ways of managing interrelationships.

Jim Noble, General Motor's head of IT strategy, is involved in a transformation that involves extending value chain activities. 'We've been trying to create a new value chain, because the old model no longer serves us well' [48]. This involves consideration of 100 million customers; in the past customer information was not shared among brands (e.g., Buick, Cadillac, Chevrolet, or Oldsmobile), presently an enterprise-wide system promotes such exchange. 'More than 50 per cent of US households have never bought a vehicle new. We can't ignore half the US market. By extending our value chain downstream, we' re moving into services' [49]. With the addition of two-way communication between vehicle and automaker, on-board information gathering systems allow improvement of existing services and creation of new services. 'Metered insurance, for example — not annual insurance for a fixed fee - by figuring out how often you drive, whether your antilock breaking system activates frequently, and so on' [50]. Assessing strategic linkages and interrelationships leads to an honest understanding/awareness of firm capabilities and limitations, providing the flexibility to signal as well as navigate opportunities and threats.

For some, upstream and downstream are not figurative, not a metaphor. Upstream real-time measurement can lead to automated reaction - the addition of chemicals to treat the water source. Upstream analysis can literally lead to proactive adjustments of downstream water flow and use of energy (a primary input for transmission and distribution) coincident with off-peak rates. Process control systems for the water value chain may satisfy regulatory record keeping while managing operations costs at the same time as improving quality of the product [51]. Taking the value chain's pulse. Dell Computer manages the flow of product by balancing supply and demand. Dell materials manager Mike Gray indicates that if 10-gigabyte hard drives are in short supply, temporary disincentives can be installed to influence demand of products incorporating them. Similarly, incentives influencing demand can be put in place for machines utilizing particular components if a supplier offers savings on such parts [52]. It has recently been suggested that there exists a 'social value chain' [53]. This entails the arrangement of social relationships in a community that involve collaboration and sharing to create value. 
Although value chain analysis has historically centred on eliminating waste (and likely will continue to do so), recent evidence indicates that increased sales, improved quality and customer service, greater market share, and accelerated delivery times are likely results attributable to properly tuned value chains [54]. This survey indicates having an active strategy for the value chain is a key ingredient. Findings indicate realised rewards from a 'holistic approach', 'advanced and innovative connectivity', 'tightly integrated' systems and processes, and 'communities formed' to avoid 'silos' [55].

A firm' $s$ ability to identify and manage linkages and interrelationships is a critical element in responding to competitive forces. This paper suggests that value chain analysis can be a powerful tool in developing strategy. 'Though linkages within the value chain are crucial to competitive advantage, they are often subtle and go unrecognized. ... Identifying linkages is a process of searching for ways in which each value activity affects or is affected by others' [56]. The strategic development and management of linkages is a far more complex organizational task than managing the value activities themselves. Given the difficulty of recognising and managing linkages and interrelationships, the very ability to do so becomes an important source of sustainable competitive advantage.

\section{Acknowledgement}

Will Acar, Charles Dhanaraj and Bernard Taylor were helpful in shaping this paper and are exonerated from any errors. Support as a Fulbright Scholar from the Foundation for Educational Exchange between Canada and the US, the Institute of International Education and the J.M. Smucker Company is gratefully acknowledged.

\section{References}

[1] Porter, M.E., Competitive Advantage: Creating and Sustaining Superior Performance, New York, NY: Free Press 1985.

[2] Ibid.

[3] Ibid, p. 2.

[4] Reed, R. and DeFiilippi, R.J., 'Causal Ambiguity, Barriers to Imitation, and Sustainable Competitive Advantage', Academy of Management Review, Vol. 15, No. 1, 1990, pp. 88102.

[5] Ibid.

[6] Hofer, C.W. and Schendel, D., Strategy Formulation: Analytical Concepts, St. Paul, MN: West Publishing, 1978.

[7] Reed and DeFillipi, 1990, op. cit. 
[8] Porter, 1985, op. cit.

[9] Burcham, R., 'New Pharma Business Model: Can You Survive IT?', Pharmaceutical Executive, Vol. 20, No. 11, 2000, pp. 94-100.

[10] Ibid, p. 95.

[11] O'Sullivan, L. and Geringer, J.M., 'Harnessing the Power of Your Value Chain', Long Range Planning, Vol. 26, No. 2, 1993, pp. 59-68.

[12] Ibid, p. 60.

[13] Armistead, C.G, and dark, G., 'Resource Activity Mapping: The Value Chain in Service Operations Strategy', Service Industries Journal, Vol. 13, No. 4, 1993, pp. 221-239.

[14] Mahoney, J.T. and Pandian, J.R., 'The Resource-Based View Within the Conversation of Strategic Management', Strategic Management Journal, Vol. 13, No. 5, 1992, pp. 363380.

[15] Peteraf, M.A., 'The Cornerstones of Competitive Advantage: A Resource-Based View', Strategic Management Journal, Vol. 14, No. 3, 1993, pp. 179-191.

[16] Teece, D., G. Pisano, \& Shuen, A. Dynamic capabilities and strategic management. Strategic Management Journal. Vol. 18, No. 7,1997, pp. 509-533.

[17] Ealy, L., 'Metamorphosis: A Critical Appraisal of the Global Auto Industry's Future', Motor Business International, Vol. 1, No. 3, 1999, pp.162-170.

[18] Ibid.

[19] Author's interviews at Ericsson Research Canada, Montreal, Quebec.

[20] Porter, 1985, op. cit., p. 48.

[21] Shapiro, J.F., Singhal, V.M. and Wagner, S.N., 'Optimizing the Value Chain', Interfaces, Vol. 23, No. 2, 1993, pp. 102-117.

[22] Porter, 1985, op. cit.

[23] Ibid., p. 49.

[24] Ibid.

[25] Ibid.

[26] St John, C.H. and Harrison, J.S., 'Manufacturing-Based Relatedness, Synergy, and Coordination', Strategic Management Journal, Vol. 20, No. 2, 1999, pp. 129-145.

[27] Burcham, 2000, op. cit.

[28] Ibid.

[29] Ibid., p. 98.

[30] Sheridan, J.H., 'Focused on Flow', IndustryWeek, Vol. 248, No. 19, 1999, pp. 46-48.

[31] Taninecz, G. 'Forging the Chain', IndustryWeek, Vol. 249, No. 10, 2000, pp. 40-45.

[32] Talluri, S., Baker, R.C., and Sarkis, J., 'A Framework for Designing Efficient Value Chain Networks', International Journal of Production Economics, Vol. 62, No. 2, 1999, pp, 133144. 
[33] Mahoney, J.T., 'The Choice of Organizational Form: Vertical Financial Ownership Versus Other Methods of Vertical Integration', Strategic Management Journal, Vol. 13, No. 8, 1992, pp. 559-584.

[34] Ealy, 2000, op. cit., p. 167.

[35] Ibid., p. 167.

[36] Quinn, J.B., 'Leveraging Intellect', Executive Excellence, Vol. 10, No.10, 1993, pp.7-8.

[37] Fingar, P., 'Vital Value Chains', Computer World, Vol. 34, No. 28, 2000, p.34.

[38] Ibid., p. 34.

[39] Rockart, J.F. and Short, J.E., 'IT in the 1990s: Managing Organizational Interdependence', Sloan Management Review, Vol. 30, No. 2, 1989, pp.7-17.

[40] Ibid., p. 11.

[41 ] Pickering, J.F. and Matthews, D., 'Managing Patents for Competitive Advantage', Journal of General Management, Vol. 25, No. 3, 2000, pp.15-32.

[42] Papazoglou, M.P., Ribbers, P., and Tsalgatidou, A., 'Integrated Value Chains and their Implications from a Business and Technology Standpoint', Decision Support Systems, Vol. 29, No. 4, 2000, pp. 323-342.

[43] Porter, 1985, op. cit.

[44] Hall, R., 'The Strategic Analysis of Intangible Resources', Strategic Management Journal, Vol. 13, No. 2, 1992, pp. 135-144.

[45] Ealy, 2000, op. cit.

[46] Barnatt, C., 'e-Legacy: The IP Systems Challenge', Journal of General Management, Vol. 25, No. 4, 2000, pp. 1-16.

[47] Parker, J., 'Lean, Mean, Vulnerable... Up the Value Chain', TrafficWorld, Vol. 263, No. 13, 2000, p. 25.

[48] Harris, P., 'GM Will Use Technology to Know its Customers', InformationWeek, Iss. 763, 1999, pp. 153-154.

[49] Ibid., p. 154.

[50] Ibid., p. 154.

[51] Brueck, T.M. and Cassidy, P.O., 'Optimizing the Water Business Enterprise', Water Engineering \& Management, Vol. 147, No. 9, 2000, pp. 53-56.

[52] Sheridan, 1999, op. cit.

[53] Kanter, R.M., 'Knowledge Exchange', Executive Excellence, Vol. 17. No. 11, 2000, pp. 3-4.

[54] Schuiz, J.D., 'Value Chain Confusion', TrafficWorld, Vol. 263, No.8, 2000, pp.18-19.

[55] Ibid.

[56] Porter, 1985, op. cit., p. 50. 